\title{
Differential expression and functional analysis of two short-chain alcohol dehydrogenases/reductases in Hedychium coronarium
}

\author{
Hua Chen ${ }^{1}$, Yuechong Yue ${ }^{2,3}$, Rangcai Yu ${ }^{2,3}$, Yanping Fan ${ }^{2,3, *}$ \\ ${ }^{1}$ Department of Landscape Architecture, College of Life Science, Zhaoqing University, Zhaoqing 526061, China \\ ${ }^{2}$ The Research Center for Ornamental Plants, College of Forestry and Landscape Architecture, South China \\ Agricultural University, Guangzhou 510642, China \\ ${ }^{3}$ Guangdong Key Laboratory for Innovative Development and Utilization of Forest Plant Germplasm, \\ South China Agricultural University, Guangzhou 510642, China
}

\begin{abstract}
In this study, the full cDNA sequences of $\mathrm{HcADH} 2$ and $\mathrm{HcADH} 3$ were cloned from Hedychium coronarium. The amino acid sequences encoded by them contained three most conserved motifs of short-chain alcohol dehydrogenase (ADH), namely $\mathrm{NAD}^{+}$binding domain, TGxxx[AG]xG and active site YxxxK. The highest similarity between two genes and ADH from other plants was $70 \%$. Phylogenetic analysis showed that they belonged to a member of the short-chain dehydrogenases/ reductases $110 \mathrm{C}$ subfamily, but they were distinctly clustered in different clades. Real-time polymerase chain reaction analyses showed that $H c A D H 2$ was specifically expressed in bract, and it was expressed higher in no-scented Hedychium forrestii than other Hedychium species, but was undetectable in Hedychium coccineum. HcADH3 was expressed higher in the lateral petal of the flower than in other vegetative organs, and it was expressed the most in H. coronarium that is the most scented among Hedychium species, and its expression levels peaked at the half opening stage. HcADH2 and HcADH3 had almost no significant expression in leaves, but $H C A D H 2$ was expressed in response to external stimuli. The mechanical injury and methyl jasmonate (MeJA) treatment could induce expression of HcADH2 in leaves, whereas HcADH3 could have an induced expression only by MeJA. The recombinant HcADH3 protein, but not HcADH2, expressed in Escherichia coli-catalysed conversion of geraniol into citral. It was speculated that $\mathrm{HcADH} 3$ had an induced expression in vegetative organ of $H$. coronarium and took part in monoterpenoid biosynthesis in $H$. coronarium flowers, but the role of HcADH2 is relevant only for defensive reactions.
\end{abstract}

Keywords: expression analysis, function, Hedychium coronarium, short-chain alcohol dehydrogenase/reductase

Abbreviations:

$\mathrm{ADH}$, alcohol dehydrogenase; GC-MS, gas chromatography-mass spectrometry; IPTG, isopropyl-1-thio- $\beta$-D-galactoside; MeJA, methyl jasmonate; PAGE, polyacrylamide gel electrophoresis; RT-PCR, reverse transcription polymerase chain reaction.

\section{INTRODUCTION}

Hedychium coronarium is a perennial herb that belongs to the Hedychium genus of the Zingiberaceae family. The genus Hedychium approximately contains 60 species (Wu, 1994). According to the olfactory sensory evaluation, four different species of Hedychium genus were selected, namely, Hedychium coccineum Buch.Ham (scentless), Hedychium forrestii (scentless), Hedychium gardnerianum (slightly fragrant) and 
H. coronarium (fragrant)(Fan etal., 2007).H. coronarium commonly grows in woodland shrubs at the altitude of 600-2,100 m, which is often cultivated as a horticultural garden plant because of its rich fragrant flowers. It can also be used in excavated medicine and aromatic oil (Wu and Raven, 2001). The volatile compounds mainly consist of monoterpenes, monoterpene derivatives, sesquiterpene and benzenoids, including linalool, $(E) /(Z)$ - $\beta$-ocimene, 1,8-cineole, sabinene, $\alpha$-thujene, myrcene, $\alpha / \beta$-pinene, allo-ocimene, $\alpha$-farnesene and $\beta$-caryophyllene at the blooming stage of $H$. coronarium flowers (Fan et al., 2007; Baez et al., 2011).

$H$. coronarium is often called a white ginger lily. Its flowers are white and not bright, but they are very fragrant. Therefore, it is an ideal material to study the secondary metabolism of horticultural plant flowers. However, there have been few research on secondary metabolism that is related to the development physiology of $H$. coronarium, such as fragrance, defence, etc. (Yue et al., 2014; Chen et al., 2019). Chemical constituents of the rhizomes of $H$. coronarium had an inhibitory effect on lipopolysaccharide-stimulated production of pro-inflammatory cytokines in bone marrow-derived dendritic cells (Kiem et al., 2011). The new full-length cDNA that encoded farnesyl diphosphate synthase from $H$. coronarium was possibly involved in the biosynthesis of floral and wounding/herbivory-induced leaf volatile sesquiterpenoids (Lan et al., 2013).

Furthermore, short-chain dehydrogenase/reductases (SDRs) are a gene family involved in various secondary metabolic pathways. At present, the research on cloning of SDR genes has mainly been focused on dicots, such as genus Solanum (Sonawane et al., 2018), Catharanthus roseus (Stavrinides et al., 2018), Scopolia lurida (Zhao et al., 2017), Hevea brasiliensis (Loh et al., 2016), Camellia sinensis (Zhou et al., 2015), Medicago truncatula (Pan et al., 2014), Papaver somniferum (Chen and Facchini, 2013; Ziegler et al., 2009), Lycopersicon esculentum Mill. (Moummou et al., 2012), Gossypium spp. (Pang et al., 2010), Panax ginseng (Kim et al., 2009), Solanum tuberosum L. (Keiner et al., 2002), Citrullus lanatus (Thunb.) Matsum. et Nakai (Kim et al., 2003), Arabidopsis thaliana (Cheng et al., 2002), etc., while few reports had been on monocots. The momilactone, a synthase (OsMAS/SDR110C-MS1) of Oryza sativa with the other four - all falling in the same SDR110C family, had roles in diterpenoid biosynthesis (Kitaoka et al., 2016). The first step of chlorophyll $b$ degradation in rice can be catalysed by a membrane-localised SDR (Sato et al., 2008). Zingiber zerumbet, a member of the Zingiber genus of Zingiberaceae family, is widely cultivated throughout the tropics and the subtropics for its medicinal properties. The rhizome oil of $Z$. zerumbet contains a high content of sesquiterpenoids with zerumbone, and ZSD1 (BAK09296.1) was cloned from Z. zerumbet and belonged to a member of the SDRs 110C subfamily (http://www.sdr-enzymes.org) which catalysed 8 -hydroxy- $\alpha$-humulene into zerumbone and involved in secondary metabolism, stress responses and phytosteroid biosynthesis (Okamoto et al., 2011).

The expression of $S D R$ s in plants can be regulated with development or induced by external stimuli. For the former, SDR is often expressed at certain stages during development and in specific tissues, for example, tuber, root, glandular hair of leaves, flower and fruit (Okamoto et al., 2011; Chen et al., 2011). As for the latter, the studies have shown that the tetramer SAD of pea has at least three similar family members (SAD-A, SAD-B and SAD-C), and mRNA expression indicated that SAD expression can be induced by the environment (Scherbak et al., 2011).

Our team has obtained the whole transcriptome sequence of $H$. coronarium (Yue et al., 2015). Among them, there are 10 sequences of short-chain alcohol dehydrogenase/reductase (SCADH). This research analysed the transcriptome of $H$. coronarium to study on secondary metabolism that is related to the development physiology of $H$. coronarium flowers. In this study, two new short-chain alcohol dehydrogenase/ reductase genes, $\mathrm{HcADH} 2$ and $\mathrm{HcADH} 3$, were cloned, respectively. In-depth analysis of expression regulation of these two genes was also performed to understand similarities and differences in the secondary metabolic function of different SDRs in $H$. coronarium. Meanwhile, prokaryotic expressions of recombinant $\mathrm{HcADH} 2$ and HcADH3 were also conducted, then different substances were added and the products were examined by GS-MS to determine the catalytic activity of the recombinant enzymes. Further studies are required to clarify their involvement in related secondary metabolic pathways of $H$. coronarium to lay a theoretical basis to fully understand secondary metabolism of $H$. coronarium.

\section{MATERIALS AND METHODS}

\section{Plant materials used to clone the genes}

$H$. coronarium was grown in the horticulture chamber in South China Agricultural University under natural light from April to November. The temperature $\left(20-30^{\circ} \mathrm{C}\right)$ and the relative humidity of the atmosphere (70-80\%) of the environmental conditions were suitable for $H$. coronarium and the plants grew well, and the fullblooming flowers were selected (Fan et al., 2007).

All plant materials were harvested, immediately frozen in liquid nitrogen and stored at $-70^{\circ} \mathrm{C}$ for RNA isolation and quantitative real-time polymerase chain reaction (PCR). All experiments were conducted three times with independently collected plants.

\section{Plant materials for analysis on the temporal and spatial expression of the genes}

According to Yue's methods (Yue et al., 2014), different tissues, i.e. flower, bract, leaf, stem, root and rhizome, and different floral parts, i.e. style and stigma, anther, 


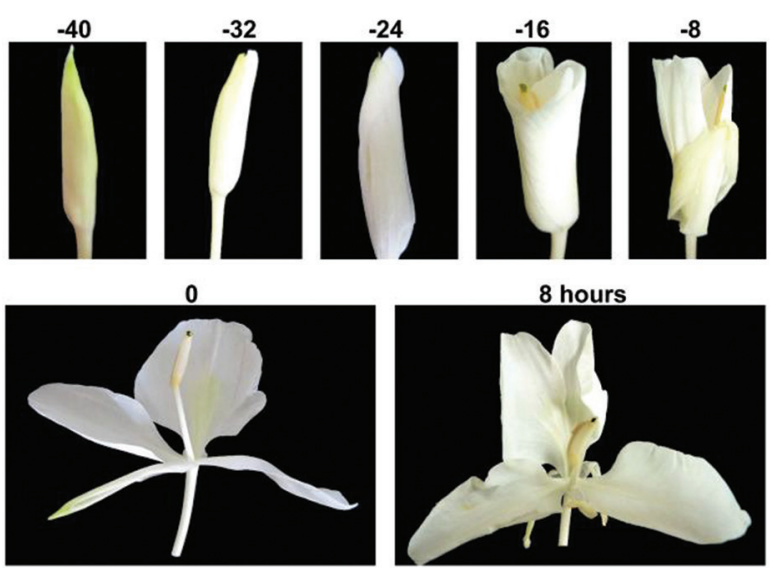

Figure 1. Photographs of $H$. coronarium flowers in different developmental stages. $-40=40 \mathrm{~h}$ pre-anthesis; $-32=32 \mathrm{~h}$ pre-anthesis; $-24=24 \mathrm{~h}$ pre-anthesis; $-16=16 \mathrm{~h}$ pre-anthesis; $-8=8 \mathrm{~h}$ pre-anthesis; $0=0 \mathrm{~h}$ anthesis; $8=8$ h post-anthesis.

filament, outer labellum, lateral petal, sepal, pedicel were harvested from $H$. coronarium for the analysis of gene expression. The development of $H$. coronarium flowers was divided into seven stages (40, 32, 24, 16 and $8 \mathrm{~h}$ pre-anthesis, $0 \mathrm{~h}$ anthesis and $8 \mathrm{~h}$ post-anthesis) (Figure 1). We selected four different species of the Hedychium genus, such as H. coccineum Buch.-Ham, $H$. forrestii, $H$. gardnerianum and $H$. coronarium. At present, these species of the Hedychium genus are widely cultivated in China.

\section{Mechanical injury treatment}

According to Lan's methods (Lan et al., 2013), the wounded leaves and control leaves (not wounded, natural leaves) were collected at 0, 3, 6, 12 and $24 \mathrm{~h}$ after treatment and immediately frozen in liquid nitrogen.

\section{MeJA treatment}

Methyl jasmonate (MeJA) was dissolved in a small volume of ethanol and diluted with distilled water to $300 \mu \mathrm{M}$ (Yu et al., 2008). After spraying MeJA, the leaves were rubbed with a layer of lanolin to prevent the volatilisation of MeJA. MeJA-treated and control leaves were harvested at $0,3,6,12,18$ and $24 \mathrm{~h}$ after treatment.

All plant materials were frozen in liquid nitrogen and stored at $-70^{\circ} \mathrm{C}$ immediately after harvesting for future isolation of RNA and quantitative real-time PCR assays. All experiments were conducted three times with independently collected materials.

\section{RNA isolation and reverse transcriptase PCR}

Total RNA was extracted with the revised hexadecyl trimethyl ammonium bromide (CTAB) method (Zhang et al., 2010). RNA content was determined spectrophotometrically. All RNA extracts were treated with DNAse (Takara Bio. Dalian, China). Of note, $1 \mu \mathrm{g}$ of RNA was reverse-transcribed in $20 \mu \mathrm{l}$ final volume reaction mixture including reaction buffer, namely $20 \mu \mathrm{mol} \cdot \mu \mathrm{l}^{-1}$ Rnase inhibitor, $1 \mathrm{mmol} \cdot \mathrm{l}^{-1}$ dNTP, $1 \mu \mathrm{g}$ oligo $(\mathrm{dT})_{18}$ and reverse transcriptase (RT) (M-MLV; Takara Bio. Dalian, China) according to the manufacturer's instructions (Li and Fan, 2011).

\section{Cloning and sequence analysis of the target gene}

Our team has obtained the whole transcriptome sequence of $H$. coronarium (Yue et al., 2015). Among them, there are 10 sequences of short-chain alcohol dehydrogenase (SAD), of which HcADH2 and HcADH3 are highly expressed. From the transcriptome of $H$. coronarium, two putative full-length SDRs sequences (comp45280 c0 and comp41433_c0) (Table S1 in Supplementary Materials) were identified as short-chain alcohol dehydrogenase/reductase using the inquiry sequence in BLAST searches. The two genes were clustered and analysed with the known SDR genes, which showed that they were closely related to the genes involved in the secondary metabolism of $H$. coronarium, so these two genes were chosen to carry out further research related to the secondary metabolism of $H$. coronarium. Biological software Primer Premier 5.0 was used to design specific primers (Table S2 in Supplementary Materials) to clone the full cDNA sequences. The primers were synthesised by Shanghai Sangon Biological Engineering Co., Ltd. The full-length cDNAs were amplified using high-fidelity DNA polymerase KOD-Plus (TOYOBO) following the manufacturer's recommendation. The PCR conditions were as follows: $94^{\circ} \mathrm{C}$ for $2 \mathrm{~min}$, followed by 35 cycles at $98^{\circ} \mathrm{C}$ for $15 \mathrm{~s}, 55^{\circ} \mathrm{C}$ for $30 \mathrm{~s}, 68^{\circ} \mathrm{C}$ for $2 \mathrm{~min}$. The product was ligated into the pMD-19 vector after the A base was added on 3' end by TaqDNA polymerase. The obtained plasmid DNA was sequenced.

The predicted protein sequences alignment was performed using the DNAssist version 2.2 software; the identity value was calculated by DNAMAN version 5.2.2 software and the construction of a phylogenetic tree was conducted by alignment on ClustalX at first, followed by neighbour-joining with MEGA software (version 5.05) (Kumar et al., 2004). The numbers at each branch indicate bootstrap percentages from 1,000 replicates. The evolutionary distances were computed using the model of Poisson correction. Positions containing gaps and missing data were eliminated. The scale bar indicates $20 \%$ sequence divergence. GenBank accession numbers are shown in Table S3 in Supplementary Materials.

An identity search for translated amino acids was conducted using the National Center for Biotechnology Information (NCBI) BLAST network server (http:// www.ncbi.nlm.gov/BLAST).

\section{Quantitative real-time PCR assays}

Primers for quantitative real-time PCR were designed using Primer Premier version 5.0 (Table S4 in Supplementary Materials), and the dissolution curve suggested that only a single PCR product was amplified by each pair of primers. To ensure the specificity of the primers for amplification of the target gene, we further 
sequenced the PCR product of each pair of primers. $G A P D H$ was used as the internal control gene in this study.

Real-time RT-PCR was performed in a volume of $20 \mu 1$ containing SYBR Premix Ex TaqTM with an ABI 7500 real-time PCR system. The PCR conditions were as follows: $95^{\circ} \mathrm{C}$ for $30 \mathrm{~s}$, followed by 40 cycles at $95^{\circ} \mathrm{C}$ for $5 \mathrm{~s}$, annealing at $55^{\circ} \mathrm{C}$ for $30 \mathrm{~s}$, elongation at $72^{\circ} \mathrm{C}$ for $30 \mathrm{~s}$. The melting curve was designed to increase $0.4^{\circ} \mathrm{C}$ every $10 \mathrm{~s}$ from 72 to $94^{\circ} \mathrm{C}$. All real-time PCR analyses were performed in triplicate with different cDNAs synthesised from three biological replicates. The amplicon was clarified using electrophoresis and sequenced once for identity confirmation. Quantification was done for the analysis of the threshold cycle $(\mathrm{Ct})$ value. According to Manríquez's methods, the relative expression ratios were quantified (Manríquez et al., 2006).

\section{Heterologous expression of $\mathrm{HCADH} 2$ and HCADH3 in Escherichia coli}

The entire open reading frame of $\mathrm{HcADH} 2$ and $\mathrm{HcADH} 3$ were constructed using a pET30a vector to express $\mathrm{HcADH} 2$ and HcADH3, respectively, as a His-tagged protein(Table S2 in Supplementary Materials). Expression, solubility analysis and purification of the target protein were performed using Yue's methods (Yue et al., 2014). The recombinant plasmid pET30a-HcADH2 and pET30aHcADH3 were transformed into E. coli Rosetta (DE3) competent cells (Invitrogen). Single positive colonies verified by sequencing were inoculated at $37^{\circ} \mathrm{C}$ overnight, shaking continuously in $5 \mathrm{ml}$ Luria Bertani (LB) liquid medium supplemented with $0.1 \mathrm{mg} \cdot \mathrm{ml}^{-1}$ kanamycin. Then the grown cultures were diluted 1:50 with LB medium under the same conditions as above until OD600 of $0.4-0.5$ at $37^{\circ} \mathrm{C}$ was achieved. Cultures were then induced with $0.05 \mathrm{mM}$ isopropyl-1-thio- $\beta$-D-galactoside (IPTG) and incubated for an additional $14 \mathrm{~h}$ at $16^{\circ} \mathrm{C}$ and $180 \mathrm{rpm}$ with shaking. The cells were separated from the medium by centrifugation $\left(5,000 \mathrm{~g}, 5 \mathrm{~min}, 4^{\circ} \mathrm{C}\right)$ and resuspended in $5 \mathrm{ml}$ lysis buffer $\left(50 \mathrm{mM} \mathrm{NaH}_{2} \mathrm{PO}_{4}, \mathrm{pH} 8.0,300 \mathrm{mM}\right.$ $\mathrm{NaCl}, 10 \mathrm{mM}$ imidazole). Cells were then sonicated three times (work $3 \mathrm{~s}$ with $3 \mathrm{~s}$ intervals at $4^{\circ} \mathrm{C}$, repeated 30 times) and the resulting suspension was centrifuged at $12,000 \mathrm{~g}$ and $4^{\circ} \mathrm{C}$ for $10 \mathrm{~min}$. The obtained crude extract was loaded onto a Ni-NTA His·Bind Resins (Novagen) to purify His-tagged recombinant protein according to manufacturer's introduction. Partially purified proteins were dialysed against a buffer containing $30 \mathrm{mM}$ 2-[4-(2-Hydroxyethyl)-1-piperazinyl] ethanesulfonic acid (HEPES) (pH 7.5) and $5 \mathrm{mM}$ dithiothreitol (DTT). The purity of the recombinant protein from each elution was estimated using sodium dodecyl sulfate (SDS) polyacrylamide gel electrophoresis (SDS-PAGE).

\section{Enzyme assay in vitro and production identification}

The enzyme assays were performed in a total volume of $1 \mathrm{ml}$ with $20 \mathrm{mM} \mathrm{KH}_{2} \mathrm{PO}_{4}, \mathrm{pH} 8.0,50 \mu \mathrm{g}$ of an enzyme,
$1 \mathrm{mM} \mathrm{NAD}(\mathrm{H}), 10 \mathrm{mM}$ EDTA and $0.1 \mathrm{mM}$ substrate. The mixture was incubated for $1 \mathrm{~h}$ at $37^{\circ} \mathrm{C}$ with shaking $(60 \mathrm{rpm})$, and the reaction was immediately stopped by the extraction of ethyl acetate $(150 \mu 1)$.

Headspace extraction and injection were conducted using a solid-phase microextraction (SPME) Fiber Assembly $\quad 50 / 30 \quad \mu \mathrm{M}$ divinylbenzene/Carboxen ${ }^{\mathrm{TM}}$ / polydimethylsiloxane (PDMS) (Stable Flex ${ }^{\mathrm{TM}}$ for manual holder grey). After incubation, the PDMS fibre was injected into a gas chromatography-mass spectrometer (GC-MS) system for analysis. The GCMS analyses were performed using an Agilent 7980A GC/5975C MSD. The instrument was equipped with an Agilent DB-5MS capillary column $(30 \mathrm{~m} \times 0.25 \mathrm{~mm})$ and helium as a carrier gas at a constant flow of $1 \mathrm{ml} \cdot \mathrm{min}^{-1}$. The oven temperature was initially maintained at $40^{\circ} \mathrm{C}$ for $2 \mathrm{~min}$, followed by an increase to $250^{\circ} \mathrm{C}$ at a rate of $5^{\circ} \mathrm{C} \cdot \mathrm{min}^{-1}$, and held at $250^{\circ} \mathrm{C}$ for $5 \mathrm{~min}$. The products were identified by comparison of mass spectra and retention time with authentic standards with the NIST2008 mass spectral library. Controls were carried out in the absence of $\mathrm{NAD}(\mathrm{H})$ and an empty vector.

\section{Headspace analysis of floral volatiles}

According to Chen's methods (Chen et al., 2019), $H$. coronarium flowers from each stage were enclosed in a $100 \mathrm{ml}$ glass bottle with the addition of ethyl decanoate as an internal standard. The flower volatiles were absorbed by PDMS (with $50 / 30 \mu \mathrm{m}$ divinylbenzene/ Carboxen) fibre (Supelco) for SPME for $30 \mathrm{~min}$. Then, the fibre was injected into a GC-MS system (Agilent) for analysis as is described earlier.

\section{RESULTS}

\section{Cloning and sequence analysis of $\mathrm{HcADH} 2$ and HcADH3}

Among the transcriptome of $H$. coronarium, there are 10 sequences of SAD, of which comp45280_c0 and comp41433_c0 are highly expressed. So these two clones were selected and identified as short-chain alcohol dehydrogenase/reductase. The PCR amplification was carried out to get the two genes designated as HcADH2 (MK388796.1) and HcADH3 (MK388797.1) using the full-length primer. The nucleotide sequences of 849 and $903 \mathrm{bp}$, respectively, were obtained (Figures S1 and S2 in Supplementary Materials). The full-length cDNAs of $\mathrm{HCADH} 2$ and $\mathrm{HcADH} 3$ contained putative open reading frames (ORFs) of 834 and $888 \mathrm{bp}$, which encoded 278 and 296 amino acid residues with predicted molecular weights of 29.00 and $31.08 \mathrm{kDa}$, respectively.

The TGxxx[AG] $x G$ motif is present in the sequences of $\mathrm{HcADH} 2$ and $\mathrm{HcADH} 3$, which is highly conserved in almost all SDRs and is responsible for Rossmann-fold scaffold due to its ability to bind $\mathrm{NAD}(\mathrm{P})$ dinucleotides (Joernvall et al., 1995; Kallberg et al., 2002) (Figure 2). Both sequences have the typical motif of YxxxK at the 


\begin{tabular}{|c|c|c|c|}
\hline RWR85228 & 1 & - RLEGKVALITGGAKGIGEVT & 29 \\
\hline HCADH2 & 1 & -VPASPSRRLEGKVAETITGGAAGSGEAT & 37 \\
\hline $\mathrm{HCADH}$ & 1 & - NLEGKVAVITGGASGIGEAT & 24 \\
\hline BAK09296 & 1 & KVALVTGGASGIGESI & 21 \\
\hline RWR94702 & 1 & MALFLQKALLRNTSRRSVLMLKDWNSSRERNKGRQLSTEAGSCS KKLA & 64 \\
\hline HCADH 3 & 1 & MLGMALRVKRG----LAIRTGIRTQQ----QQESTHP-TPAELAGKVAIITGAASGVGRAT & 52 \\
\hline RWR85228 & 30 & ¿CD & 92 \\
\hline $\mathrm{HCADH} 2$ & 38 & 党 & 101 \\
\hline HCADH & 25 & SDV & 88 \\
\hline BAK09296 & 22 & CDVT & 85 \\
\hline RWR94702 & 65 & SCDVTQ & 126 \\
\hline $\mathrm{HCADH} 3$ & 53 & & 114 \\
\hline RWR85228 & 93 & & 153 \\
\hline HCADH 2 & 102 & & 162 \\
\hline HCADH & 89 & TKHA & 152 \\
\hline BAK09296 & 86 & MKHP & 146 \\
\hline RWR94702 & 127 & $\mathrm{~K}$ & 187 \\
\hline \multirow[t]{2}{*}{$\mathrm{HCADH} 3$} & 115 & & 175 \\
\hline & & MOTIF II & \\
\hline RWR85228 & 154 & IGGIASHAYYYASKHAV & 214 \\
\hline $\mathrm{HCADH} 2$ & 163 & VAGVASHÄYVASKHAVI & 223 \\
\hline $\mathrm{HCADH}$ & 153 & NCV̈SPAIVATPEVSYYQ---TSEEELEGL & 213 \\
\hline BAK09296 & 147 & NCVISPYAVTRESMPYLPESEMQEDALRGF & 210 \\
\hline RWR94702 & 188 & NCISPFAIPTPESTDPMS-VLYPGLDESGV & 250 \\
\hline \multirow[t]{2}{*}{ HCADH3 } & 176 & VGGLAPIAY ASLSKAAVAAAVLSAAELSKHGIRVNCISPASIPTPGIKAIR-EILPDLEEQRA & 238 \\
\hline & & MOTIF III & \\
\hline RWR85228 & 215 & VSGHNEVLDGGESIVNPSEGLFKQNP & 271 \\
\hline $\mathrm{HCADH} 2$ & 224 & YÜSGQNIIIDGGETAVNHAFGLEKNS & 279 \\
\hline HCADH & 214 & EMI---STLKGVRLKAEDIAEA LELASDESREVSGHNLMIDG-ASGVTKIFS & 263 \\
\hline BAK09296 & 211 & TFVRS-NANLKGVDLMENDVAEAVYLYATEESKYVUSGLNLVIDGGESIANHTLQVEE & 267 \\
\hline RWR94702 & 251 & EIIVG-AGVLKGANCEEVDIAKAAVYISSDDAKYVSGHNLVVDGGETVEKSIQFPPPDQ & 311 \\
\hline HCADH 3 & 239 & EMIELSSAELAGTKCEVEDVAKAATELASDEAKYISGHNLMVDGGETTSKRI & 297 \\
\hline
\end{tabular}

Figure 2. Alignment of the deduced amino acid sequences of HcADH2, HcADH3 and alcohol dehydrogenases/reductases from various plant species. RWR85228 = Cinnamomum micranthum SDR; HcADH = Hedychium coronarium SDR (KF358245); BAK09296 = Zingiber zerumbet SDR; RWR94702 = Cinnamomum micranthum secoisolariciresinol dehydrogenase. Grey boxes = identical residues; black boxes $=$ similar residues; black triangle $=$ the aspartate at position 52 of HcADH2 and position 67 of HcADH3. SDR, short-chain dehydrogenase/reductase.

active site (Kavanagh et al., 2008). The NAG motif is present in the sequences of $\mathrm{HcADH} 3$, while the NAA domain is present in the sequences of HcADH2. The NAG domain is responsible for substance specificity (Oppermann et al., 1997; Filling et al., 2002), which suggests that HcADH2 may catalyse a reaction of substances, different from $\mathrm{HcADH} 3$, thus playing a different role in $H$. coronarium. The aspartic acid at position 52 (Asp52) of HcADH2 motifs and the Asp67 of HcADH3 motifs suggest that these two enzymes may prefer NAD over NADP as a coenzyme (Kallberg et al., 2002) (Figure 2).

\section{Bioinformatics analysis of HcADH2 and Hc $A D H 3$}

Alignment of the amino acid sequence revealed that HcADH2 and HcADH3 share 41\% identity. They exhibit high identity with SDRs from other species (Figure 2). For example, HcADH2 shows $49 \%$ sequence identity to our identified HcADH (Chen et al., 2019) of H. coronarium (Genbank KF358245), while HcADH3 shows $42 \%$ sequence identity. HcADH2 shows 59\% sequence identity to SDR (Genbank RWR85228.1) and $42 \%$ sequence identity to secoisolariciresinol dehydrogenase (SDH) (Genbank RWR94702.1) of Cinnamomum micranthum f. kanehirae, while HcADH3 shows $47 \%$ and $60 \%$ sequence identity, respectively (Chaw et al., 2019). HcADH2 and HcADH3 show 49\% and $43 \%$ sequence identity to the SDR of $Z$. zerumbet (GenBank BAK09296.1), respectively (Figure 2) (Okamoto et al., 2011).

\section{Phylogenetic analysis}

Phylogenetic analysis showed that HcADH2 and HcADH3 from $H$. coronarium belonged to a member of the short-chain dehydrogenases/reductases (SDRs) $110 \mathrm{C}$ subfamily (Figure 3). HcADH2 and our identified terpene-modified HcADH (Chen et al., 2019) were distinctly clustered in the same clade, whereas 


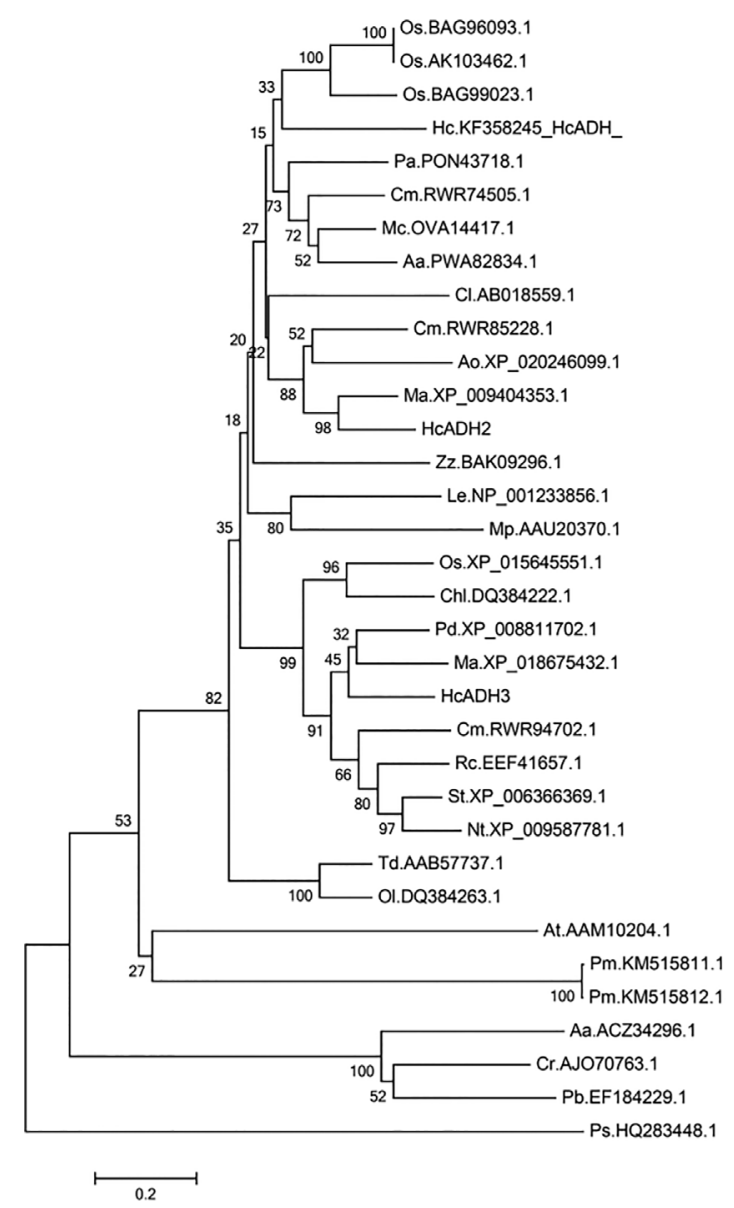

Figure 3. Phylogenetic tree of $\mathrm{HcADH} 2$ and HcADH3 with known alcohol dehydrogenase/ reductase from other species. Aa = Artemisia annua; Ao = Asparagus officinalis; At $=$ Arabidopsis thaliana; $\mathrm{Cm}=$ Cinnamomum micranthum $; \mathrm{Chl}=$ Chasmanthium latifolium; $\mathrm{Cl}=$ Citrullus lanatus; $\mathrm{Cr}=$ Catharanthus roseus $; \mathrm{Hc}=$ Hedychium coronarium $; \mathrm{Le}=$ Lycopersicon esculentum; $\mathrm{Ma}=$ Musa acuminate $; \mathrm{Mc}=$ Macleaya cordata; $\mathrm{Mp}=$ Mentha $x$ piperita $; \mathrm{Nt}=$ Nicotiana tomentosiformis; $\mathrm{Ol}=$ Orthoclada laxa; Os = Oryza sativa; $\mathrm{Pa}=$ Parasponia andersonii $; \mathrm{Pb}=$ Papaver bracteatum; $\mathrm{Pd}=$ Phoenix dactylifera $; \mathrm{Pm}=$ Persicaria minor; $\mathrm{Ps}=$ Paeonia suffruticosa; $\mathrm{Rc}=$ Ricinus communis; $\mathrm{St}=$ Solanum tuberosum; $\mathrm{Td}=$ Tripsacum dactyloides; $\mathrm{Zz}=$ Zingiber zerumbet. Scale bars $=20 \%$ sequence differences.

HcADH2 distinctly showed a close relationship with several known SDR, such as Musa acuminata subsp. malaccensis SDH (68\% identity), C. micranthum f. kanehirae SDR (53\% identity) (Chaw et al., 2019), Macleaya cordata SDR (56\% identity) (Liu et al., 2017), Artemisia annua glucose/ribitol dehydrogenase (GRD) (53\% identity) (Shen et al., 2018), Asparagus officinalis momilactone A synthase (MAS) $(60 \%$ identity) (Figure 3). However, HcADH3 was distinctly clustered in another clade, which showed close relationship with $C$. micranthum $f$. kanehirae SDH (60\% identity)
(Chaw et al., 2019), O. sativa japonica group MAS (56\% identity), Ricinus communis SAD (56\% identity) and $S$. tuberosum zerumbone synthase (ZSR) (57\% identity).

\section{Expression analysis of $\mathrm{HcADH} 2$ and $\mathrm{HcADH} 3$ genes in different tissues}

The real-time RT-PCR analysis showed that HcADH2 was most highly expressed in bracts. $H C A D H 2$ was also expressed at lower levels in stem, root and rhizome, but it was almost undetectable in leaves and flowers (Figure 4A).

As shown in Figure 4B, transcripts of $\mathrm{HcADH3}$ were preferentially expressed in flowers, with lower expression in the stem, roots and rhizome, leaf and bract. $H c A D H 3$ transcripts were highly expressed in the lateral petal of the flower, with successively lower expression in the style and stigma, sepal, filament, outer labellum and scant expression in the pedicel and anther (Figure 4C). This result showed that different SDRs genes had differential expression patterns.

\section{Expression analysis of $\mathrm{HcADH} 2$ and $\mathrm{HcADH} 3$ in different species}

The mRNA expression of $H c A D H 2$ and $H c A D H 3$ was analysed in blooming flowers of different species in the Hedychium genus (Figure 5A). HcADH2 gene was highly expressed in no-scented $H$. forrestii and at a very low level in $H$. gardnerianum and $H$. coronarium. It was barely expressed in $H$. coccineum. The highest expression of $H C A D H 3$ was noted in the very scented $H$. coronarium, and only a little expression was observed in $H$. forrestii, $H$. gardnerianum and $H$. coccineum (Figure 5B). HcADH3 perhaps has a certain correlation with flower fragrance.

\section{Expression analysis of HcADH3 during flower development}

The lifespan of a floret in a $H$. coronarium inflorescence is usually only 3 days. During flower development, there was almost scant expression of $H c A D H 3$ mRNA transcripts in petals at $40,32,24$ and $16 \mathrm{~h}$ pre-anthesis (Figure 6). Then, the HcADH3 expression levels increased sharply at $8 \mathrm{~h}$ pre-anthesis (the half opening stage), peaked at this stage and then decreased with the flower development (Figure 6), while the relative terpenes volatile aroma contents also increased sharply at $8 \mathrm{~h}$ pre-anthesis (the half opening stage) but peaked at $0 \mathrm{~h}$ (the opening stage) stage and then decreased with the flower development (Figure S3 in Supplementary Materials). This may be because the gene expression comes first and the plant traits are displayed later.

\section{HcADH2- and HcADH3-induced expression by mechanical wounding and MeJA treatment in leaves}

Both $H c A D H 2$ and $H c A D H 3$ tissue-specific expressions had almost no expression in leaves. Mechanical 
A

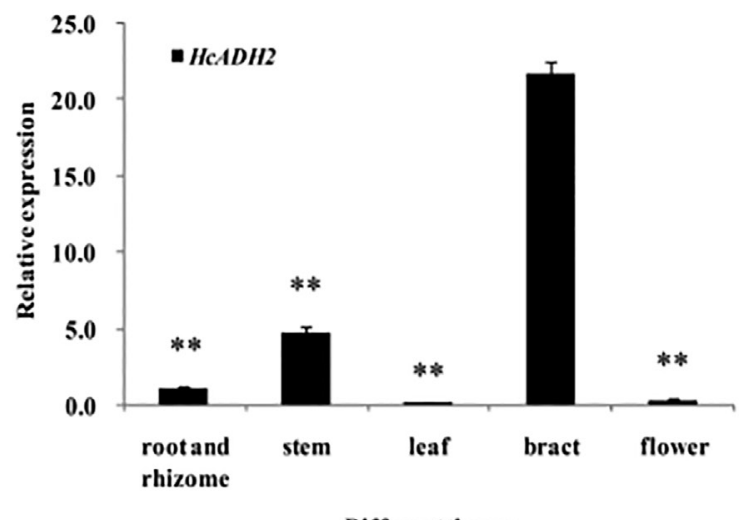

Different tissues
B

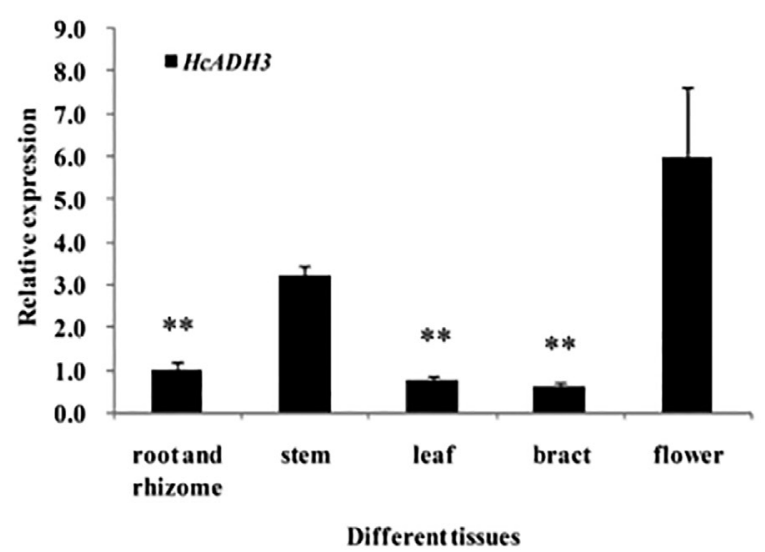

C

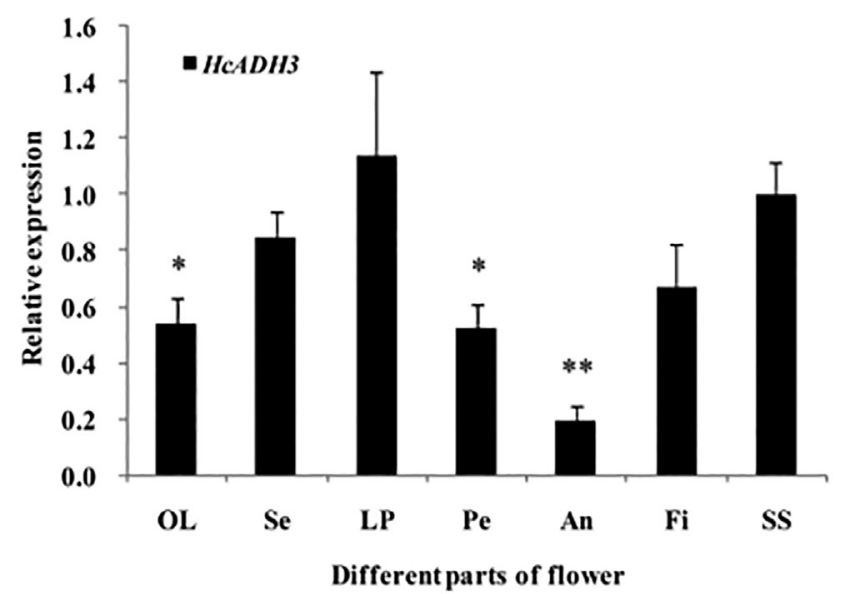

Figure 4. The expression analysis of HcADH2 and HcADH3 in different tissues of H. coronarium. (A) The HcADH2 relative expression analysis in different tissues using qRT-PCR. (B) The HcADH3 relative expression analysis in different tissues using qRT-PCR. (C) The HcADH3 relative expression analysis in different parts of flower using qRT$\mathrm{PCR} . \mathrm{OL}=$ outer abellum; $\mathrm{Se}=$ petal; $\mathrm{LP}=$ laterral petal; $\mathrm{Pe}=$ pedicel; $\mathrm{An}=$ anter $; \mathrm{Fi}=$ filament; $\mathrm{SS}=$ style and stigma. Numbers $= \pm \mathrm{SD}(n=3)$. Asterisks = statistically significant differences compared with the ones with the highest expression level $\left({ }^{*} p<0.05 ; * *<0.01\right)$.

wounding and MeJA treatment caused a significant increase in $H c A D H 2$ mRNA levels in $H$. coronarium leaves (Figure 7A and 7B). The former exhibited a fivefold increase at $3 \mathrm{~h}$ in $H c A D H 2$ mRNA levels and the latter showed a 21 -fold increase at $12 \mathrm{~h}$ compared with those in natural leaves. As shown in Figure 7C, mechanical wounding caused an irregular fluctuation in $H c A D H 3$ mRNA levels in $H$. coronarium leaves, while MeJA treatment induced a significant increase in HcADH3 mRNA levels which exhibited a sixfold increase at $12 \mathrm{~h}$ compared with those in natural leaves (Figure 7D). The results showed that $\mathrm{HcADH} 2$ was an inducible gene in the leaves which might play a defensive role in vegetative organs. However, $\mathrm{HcADH} 3$ expression can only be induced by MeJA treatment but not by mechanical wounding. This suggested that MeJA induced $H c A D H 3$ expression via the signal pathway other than injury response-related pathways.

\section{The substrate catalysis characterisation of the purified recombinant $\mathrm{HcADH} 2$ and $\mathrm{HcADH} 3$}

The coding regions of $\mathrm{HcADH} 2$ and $\mathrm{HcADH} 3$ were expressed in E. coli, and their activity was analysed in vitro. The recombinant proteins of both were purified by Niaffinity chromatography, and their activity was analysed in vitro. This experiment focused only on the selection of representatives of different structures of terpenoids as substrates, such as monoterpenoids (geraniol, camphor, linalool) and sesquiterpenoids (farnesol), for catalytic reactions (Table S5 in Supplementary Materials). The purified recombinant HcADH3 protein can convert geraniol into citral (Figure 8). However, HcADH3 could 
A

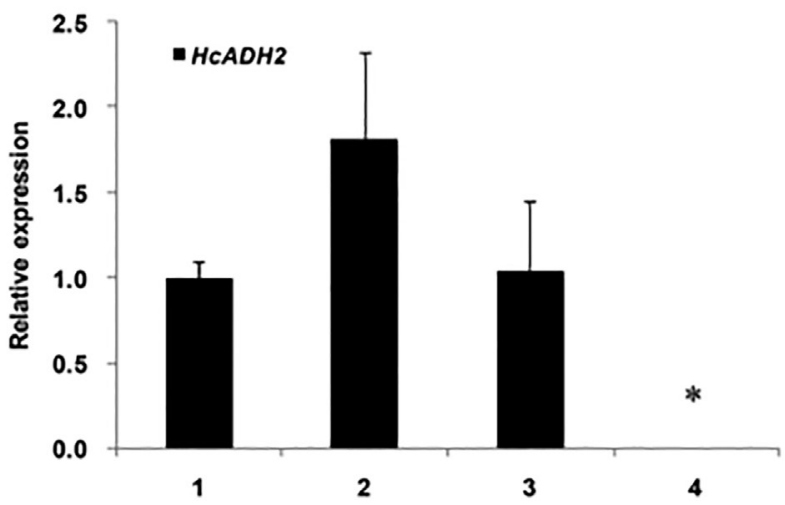

B

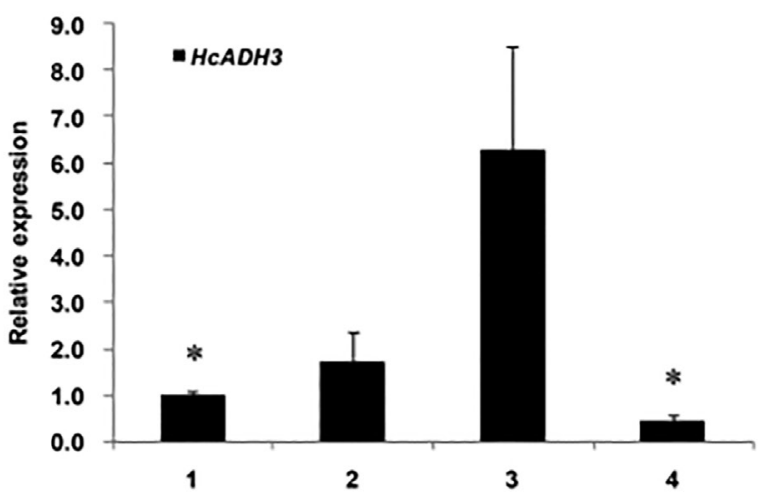

Figure 5. The expression analysis of $H c A D H 2$ (A) and $H c A D H 3$ (B) in different species of Hedychium. $1=H$. gardnerianum; $2=H$. forrestii; $3=H$. coronarium $; 4=H$. coccineum Buch. - Ham. Numbers $= \pm \operatorname{SD}(n=3)$. Asterisks $=$ statistically significant differences compared with the ones with the highest expression level $\left({ }^{*} p<0.05 ;{ }^{* *} p<0.01\right)$.

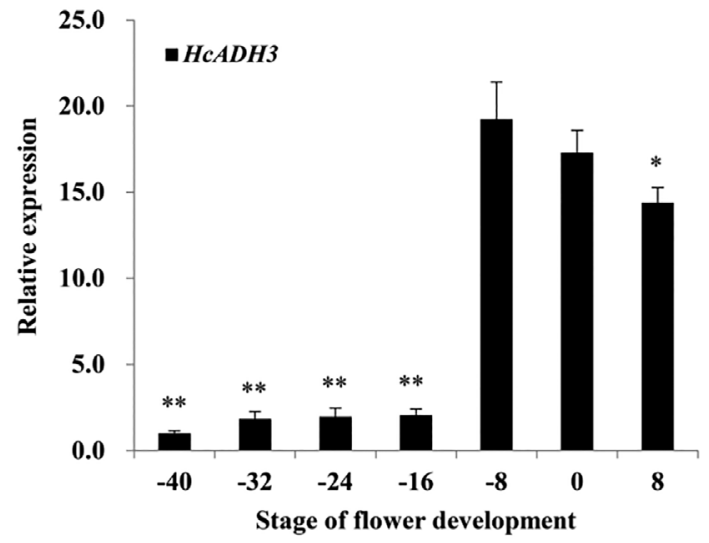

Figure 6. The expression analysis of $\mathrm{HCADH} 3$ in different developmental stages of $H$. coronarium flower. $-40=40 \mathrm{~h}$ pre-anthesis; $-32=32 \mathrm{~h}$ pre-anthesis; $-24=24 \mathrm{~h}$ pre-anthesis; $-16=16 \mathrm{~h}$ pre-anthesis; $-8=8 \mathrm{~h}$ pre-anthesis; $0=$ anthesis $(0 \mathrm{~h}) ; 8=8 \mathrm{~h}$ postanthesis. Numbers $= \pm \operatorname{SD}(n=3)$. Asterisks $=$ statistically significant differences compared with the ones with the highest expression level $(* p<0.05 ; * * p<0.01)$.

not utilise other terpenoids, including camphor, linalool and farnesol, as substrates, while purified recombinant HcADH2 protein could not catalyse geraniol, camphor, linalool and farnesol as substance. These results suggested that the coding region of $H c A D H 3$ cDNA encoded a functional alcohol dehydrogenase/reductase and might participate in dehydrogenation reactions of monoterpenoids, while recombinant $\mathrm{HcADH} 2$ protein could not encode or participate.

\section{DISCUSSION}

SDRs are divergent $\mathrm{NAD}(\mathrm{H})$ - or $\mathrm{NADP}(\mathrm{H})$-dependent enzymes including five major types, namely classical, extended, intermediate, divergent and complex. They have a wide range of substrate spectra (Kallberg et al., 2002). HcADH2 and HcADH3 belong to the 'classical' subfamily of the SDR superfamily. HcADH2 and HcADH3 are an SDR110C, identified on http://www.sdrenzymes.org (Persson et al., 2009), participating in many important secondary metabolisms (Kitaoka et al., 2016).

The temporal and spatial expression patterns of the $H c A D H s$ can provide insight into the potential roles of a short-chain alcohol dehydrogenase in $H$. coronarium. In higher plants, the function of the short-chain alcohol dehydrogenase gene should be related to gene expression, especially in different tissues, for example, the seeds (Kim et al., 2003), fibres, roots and stems (Pang et al., 2010). The analysis of fragrance-related gene expressions showed that petal epidermal cells had been proposed as the sites for scent production and emission (Vainstein et al., 2001). PsDFR1 showed the highest transcript abundance in petals, moderate levels in sepals and stamens, low level in leaves and the lowest level in carpels from petals of tree peony (Paeonia suffruticosa 'Cai Hui') (Zhou et al., 2011). The expression levels of Cucumber (Cucumis sativus L.) 18 CsSDR110C genes were different in roots, stems, leaves, male flowers, fruits and tendrils. Among these genes, the expression levels of some CsSDR110C genes can be increased in the light-induced cucumber seedlings decholorosis process (Wang, 2014). The HcADH3 gene was also highly expressed in the lateral petal of flower tissues and very low in stem, roots and rhizome, leaf and bract, which implies that $H c A D H 3$ might be a flower-related expression gene.

The expression of qRT-PCR transcript was examined at different floral developmental stages to further understand the potential role of $\mathrm{HcADH} 3$. In maize (Zea mays), a SDR protein, TASSELSEED2 (TS2) can regulate the unisexual flower development (Malcomber and Kellogg, 2006). There was a report on 
A

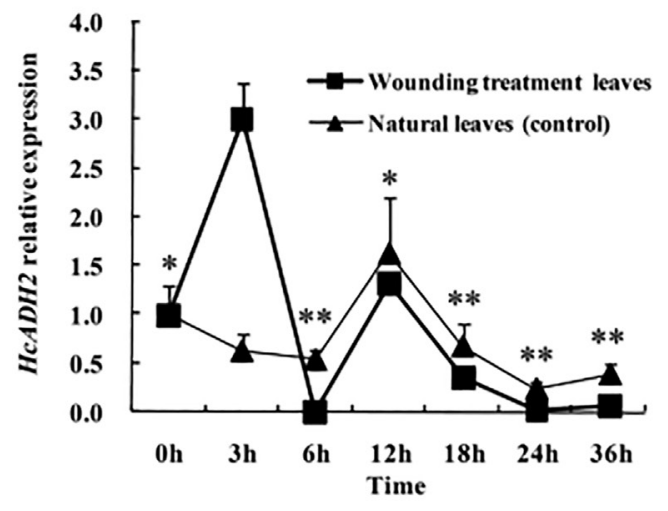

C

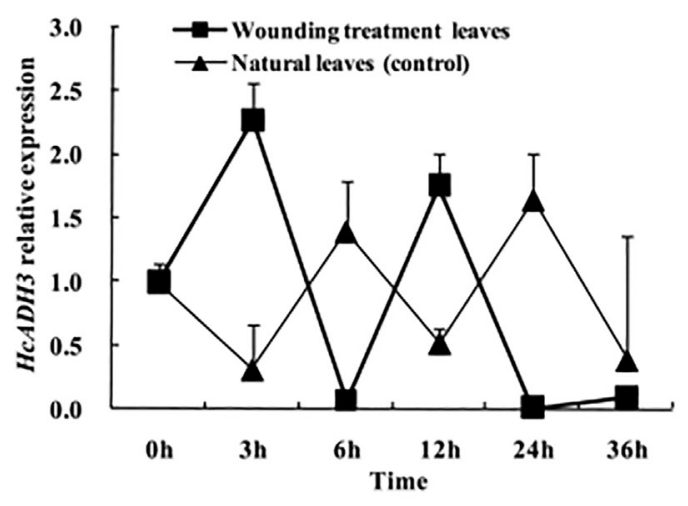

B

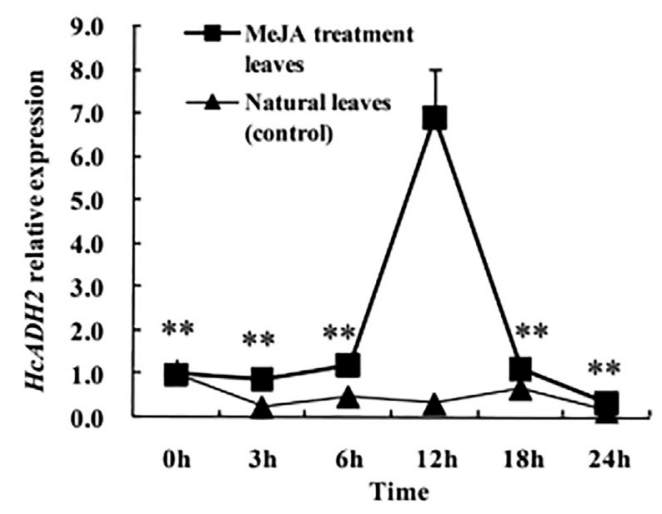

D

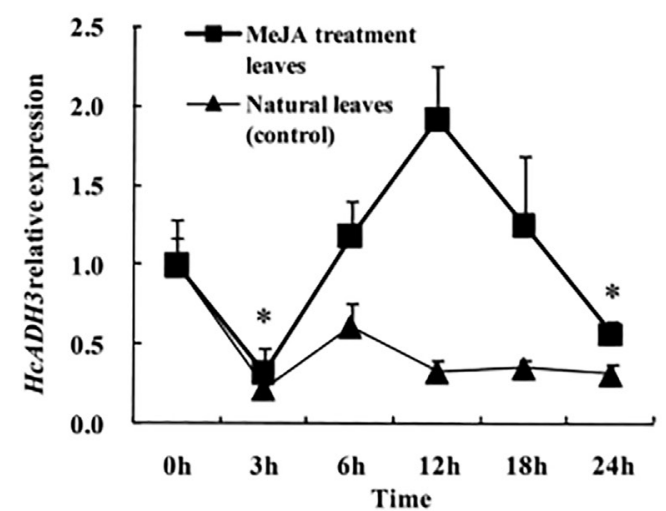

Figure 7. Expression analysis of $H C A D H 2$ and $H c A D H 3$ mRNA levels in response to external environmental stimuli. (A) $H c A D H 2$ expression at $0-36 \mathrm{~h}$ after wounding. (B) $H c A D H 2$ expression analysis of MeJA treatments and natural leaves (control) at different times. (C) $H c A D H 3$ expression at $0-36 \mathrm{~h}$ after wounding. (D) $H c A D H 3$ expression analysis of MeJA treatments and natural leaves (control) at different times. Numbers $= \pm \mathrm{SD}(n=3)$. Asterisks $=$ statistically significant differences compared with the ones with the highest expression level $\left({ }^{*} p<0.05 ;{ }^{* *} p<0.01\right)$.

the molecular cloning of GLUCOSE INSENSITIVE1 (GIN1) and ABSCISIC ACID DEFICIENT2 (ABA2), which encoded a unique Arabidopsis SDR1. SDR1 was involved in sex determination in maize (Cheng et al., 2002). The HcADH3 expression levels peaked at $8 \mathrm{~h}$ pre-anthesis (the half opening stage), but the expression levels were almost scant at 40, 32, 24 and $16 \mathrm{~h}$ preanthesis. The HcADH3 was perhaps involved in related secondary metabolic pathways of $H$. coronarium.

In Hedychium, H. coronariums is very scented through olfactory sensory evaluation (Fan et al., 2007), but some species, such as $H$. coccineum and $H$. forrestii, have lot of ornamental traits but not scented through olfactory sensory evaluation. $H$. gardnerianum is with faint scent (Wu and Raven, 2001). The transcript level of $H c A D H$ in the scent species (H. coronarium) was highest, but the gene was rarely expressed in the scentless species, such as $H$. coccineum and $H$. forrestii. The change in their expression levels in different species of the Hedychium genus was positively correlated with the emission pattern of allo-ocimene (Chen et al., 2019). $H C A D H 3$ genes are highly expressed in the flower of $H$. coronarium, which illustrates that $H c A D H 3$ is perhaps a flower fragrance-related expression gene, while $H c A D H 2$ genes showed vastly different expression characteristics. But the reasons for the $H c A D H s$ expression difference in Hedychium remain to be further verified experimentally.

In plant defence mechanisms, mechanical injury and MeJA treatments are general methods (Walter, 1992; Weeden and Provvidenti, 1988). Two SDRs $P m A D H a$ and $P m A D H b$ were conducted under the exogenous ABA treatment and drought stress in leaves, stems and roots. Exogenous ABA treatment showed that the high expression of $P m A D H s$ was tested only in roots, whereas the expression of $P m A D H a$ and $P m A D H b$ were upregulated in response to drought stress in all organs (Hamid et al., 2018). The expression of SDR1 (unique SDR) showed the dynamic mobilisation of ABA precursors and/or ABA in Arabidopsis (Cheng et al., 2002). SalR was a member of SDRs that were active as monomers and possess an extended amino acid sequence compared with classical SDRs from the opium poppy. Amino acid residues 
A

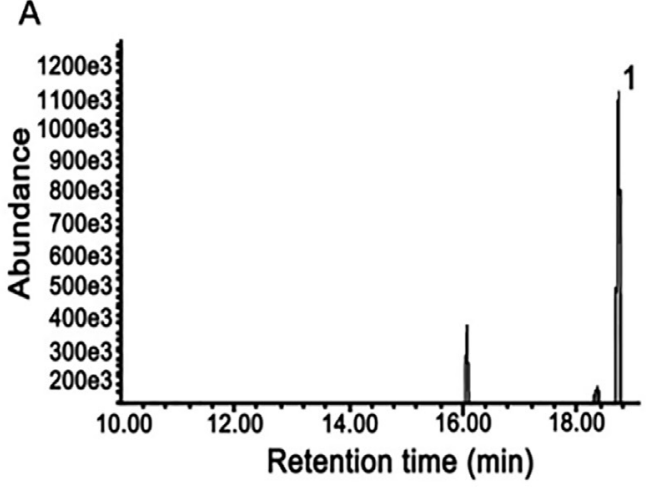

C

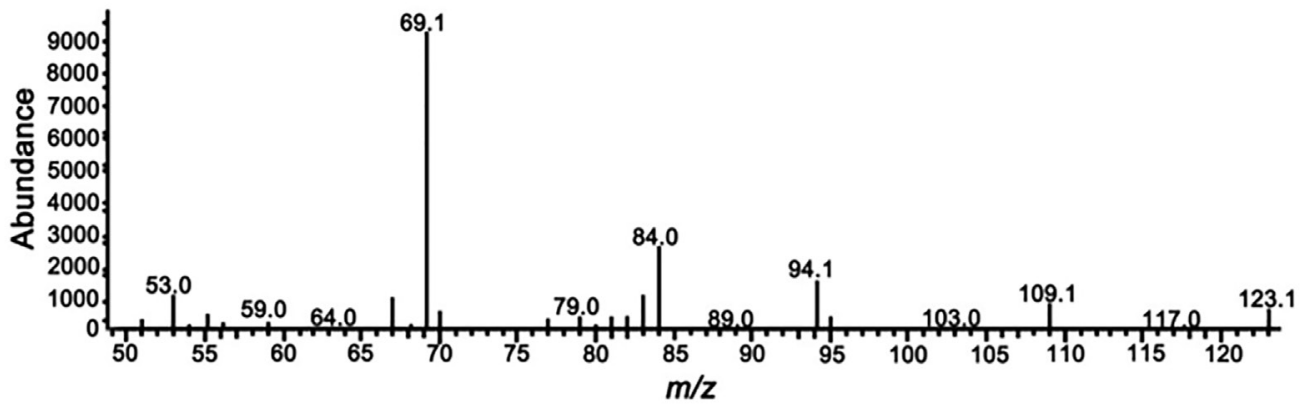

D
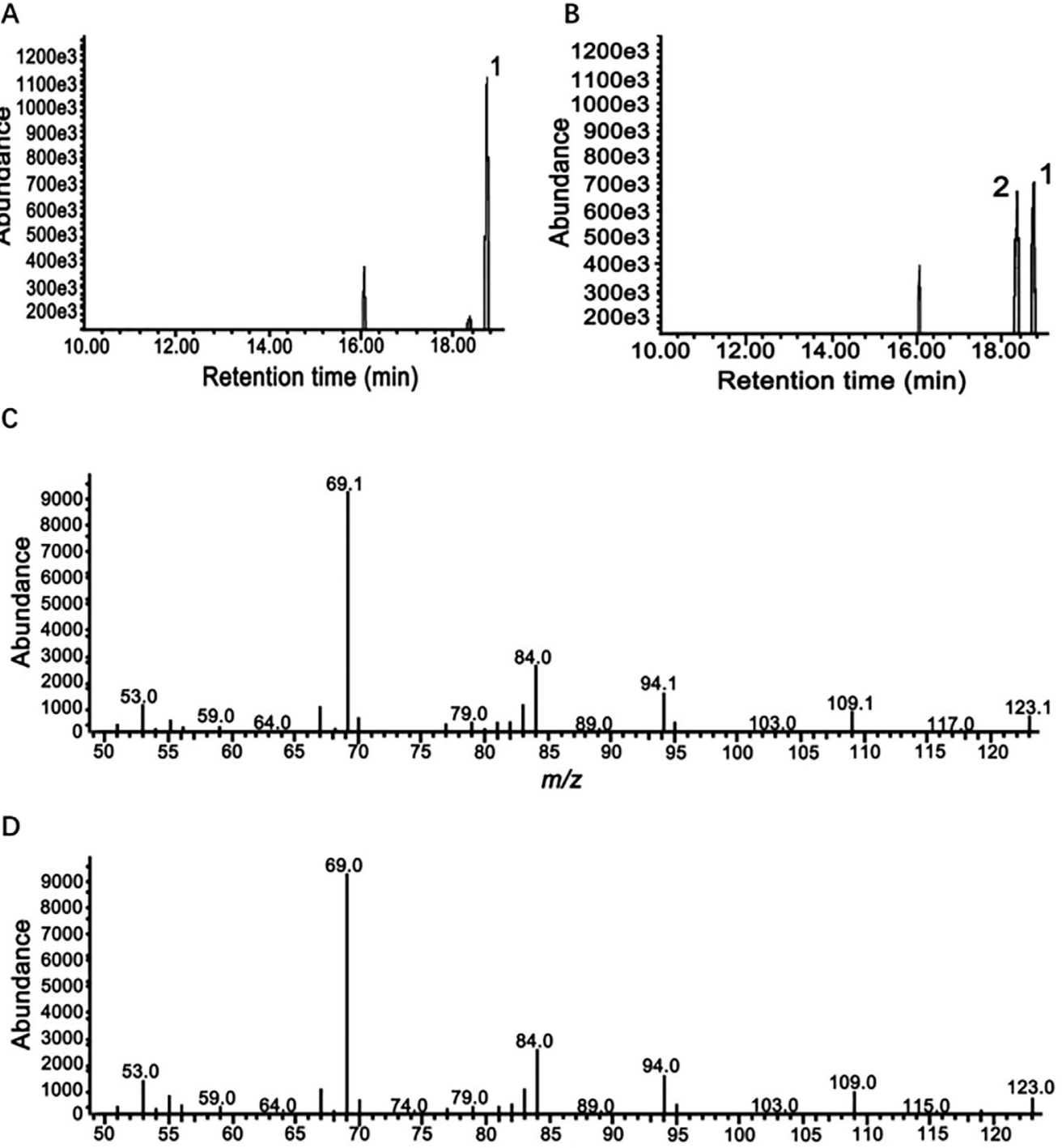

Figure 8. Analyses of products generated by the recombinant HcADH3 enzyme with geraniol as substrate. (A) Total ion chromatogram of the products obtained from the empty vector pET30a. (B) Total ion chromatogram of products obtained from pET30a-HcADH3 with NAD (peak 1, geraniol; peak 2, citral). (C) Mass spectrum of peak 2 (citral). (D) Mass spectrum of authentic citral in the NIST08 library.

conferring salutaridine binding non-specifically reduce $(-)$-menthone to (+)-neomenthol, which showed that some of these proteins are involved in plant defence (Ziegler et al., 2009). Our results suggested that treatments with mechanical wounding and MeJA in leaves of $H$. coronarium stimulated the expression of $H c A D H 2$, but $H C A D H 3$ expression was induced only by MeJA treatment. It is possible, therefore, that $\mathrm{HcADH} 2$ and $\mathrm{HCADH} 3$ also have a defensive function in $H$. coronarium vegetative organs.

Hassan et al. (2012) reported that DH I and II Polygonum minus geraniol dehydrogenase can catalyse the oxidation of geraniol to geranial, and they might be involved in monoterpene alcohol metabolism and also have their high specificity for allylic alcohols. The recombinant $\mathrm{HcADH} 3$ enzyme can use monoterpenoids geraniol as a catalytic substrate. No enzymatic product 
using pyruvaldehyde dimethyl acetal as a substrate has a $K_{\mathrm{m}}$ value of $116.52 \mathrm{mM}$ and a $V_{\max }$ value of $720 \mathrm{nmol}$ product formed per minute per milligram (Naseron et al., 2014). The GLYCOALKALOID METABOLISM 25 (GAME25) from tomato is a SDR and it catalyses to reduce the $\mathrm{C}-5,6$ double bond in dehydrotomatidine to form tomatidine. The recombinant GAME25 enzyme displayed 3 $\beta$-hydroxysteroid dehydrogenase isomerase activity on diverse steroidal alkaloid aglycone substrates and steroidal saponin aglycones (Sonawane et al., 2018). It will perhaps lay a theoretical basis to understand secondary metabolism of $H$. coronarium.

\section{CONCLUSIONS}

We have first identified two short-chain alcohol dehydrogenases/reductases in $H$. coronarium. They play different functions in $H$. coronarium. HcADH2 and $\mathrm{HcADH} 3$ have an induced expression in the vegetative organ of $H$. coronarium, but $H c A D H 3$ is also a flower-related expression gene and $\mathrm{HcADH} 3$ has catalytic activity on monoterpene and converts geraniol into citral. Our results would provide new insights into secondary metabolism of $H$. coronarium flowers.

\section{NOTES}

The nucleotide sequence reported in this article has been submitted to GenBank database with accession number, HcADH2 = MK388796.1 and HcADH3 = MK388797.1.

\section{FUNDING}

This work was supported in part by the National Natural Science Foundation of China to Yanping Fan (Grant No. 30972026, 31370694), the National Natural Science Foundation of China to Hua Chen (Grant No. 31600573), the Key platform and scientific research project of Guangdong Education Department to Hua Chen (Grant No. 2017KTSCX196), Key Laboratory of Innovation and Utilization for Germplasm Resources in Horticultural Crops in Southern China of Guangdong Higher Education Institutes, South China Agricultural University (Grant No. KBL11008) and a Specialized Research Fund for the Doctoral Program of Higher Education of China to Yanping Fan (Grant No. 20134404110016).

\section{AUTHOR CONTRIBUTIONS}

H.C. contributed to all experiments and manuscript preparation. H.C. and Y.F. designed the overall study. Y.Y. performed collection of headspace volatiles and GC-MS analysis. R.Y. performed quantitative realtime PCR assays. Y.F., Y.Y. and R.Y. helped develop the manuscript text.

\section{CONFLICT OF INTEREST}

The authors declare no conflict of interest.

\section{REFERENCES}

Baez, D., Pino, J. A., And Morales, D. (2011). Floral scent composition in Hedychium coronarium J. Koenig analyzed by SPME. Journal of Essential Oil Research, 23, 64-67.

Chaw, S. M., Liu, Y. C., Wu, Y. W., Wang, H. Y., Lin, C. Y. I., Wu, C. S., Ke, H. M., Chang, L. Y., Hsu, C. Y., Yang, H. T., Sudianto, E., Hsu, M. H., Wu, K. P., Wang, L. N., Leebens-Mack, J. H., And Tsai, I. J. (2019). Stout camphor tree genome fills gaps in understanding of flowering plant genome evolution. Nature Plants, 5, 63-73.

Chen, H., Yue, Y. C., Yu, R. C., and Fan, Y. P. (2019). A Hedychium coronarium short chain alcohol dehydrogenase is a player in allo-ocimene biosynthesis. Plant Molecular Biology, 101, 297-313.

Chen, X., And Facchini, P. J. (2013). Short-chain dehydrogenase/reductase catalyzing the final step of noscapine biosynthesis is localized to laticifers in opium poppy. The Plant Journal, 77, 173-184.

Chen, X. M., Kobayashi, H., Sakai, M., Hirata, H., Asai, T., Ohnishi, T., Baldermann, S., And WatANABE, N. (2011). Functional characterization of rose phenylacetaldehyde reductase (Par), an enzyme involved in the biosynthesis of the scent compound 2-phenylethanol. Journal of Plant Physiology, 168, 88-95.

Cheng, W. H., Endo, A., Zhou, L., Penney, J., Chen, H. C., Arroyo, A., Leon, P., Nambata, E., Asami, T., Seo, M., Koshiba, T., And Sheen, J. (2002). A unique short-chain dehydrogenase/reductase in Arabidopsis glucose signaling and abscisic acid biosynthesis and functions. Plant Cell, 14, 2723-2743.

FAn, Y. P., WANG, X. R., Yu, R. C., AND YANG, P. (2007). Analysis on the aroma components in several species of Hedychium. Acta Horticulturae Sinica, 34, 231-234.

Filling, C., Berndt, K. D., Benach, J., Knapp, S., Prozorovski, T., Nordling, E., Ladenstein, R., Jörnvall, H., And Oppermann, U. (2002). Critical residues for structure and catalysis in short-chain dehydrogenases/reductases (SDR). The Journal of Biological Chemistry, 277, 25677-25684.

Hamid, N. A. A., Zainal, Z., AND Ismail, I. (2018). Two members of unassigned type of short-chain dehydrogenase/reductase superfamily (SDR) isolated from Persicaria minor show response towards ABA and drought stress. Journal of Plant Biochemistry and Biotechnology, 27, 260-271.

Hassan, M., Maarof, N. D., Aliz, M., Noor, N. M., Othman, R., And Mori, N. (2012). Monoterpene alcohol metabolism: Identification, purification, and characterization of two geraniol dehydrogenase isoenzymes from Polygonum minus leaves. 
Bioscience, Biotechnology, and Biochemistry, 76, 1463-1470.

Joernvall, H., Persson, B., Krook, M., and Atrian, S. (1995). Short-chain dehydrogenases/reductases (SDR). Biochemistry, 34, 6003-6013.

Kallberg, Y., Oppermann, U., Jornvall, H., AND Persson, B. (2002). Short-chain dehydrogenase/ reductase (SDR) relationships: A large family with eight clusters common to human, animal, and plant genomes. Protein Science, 11, 636-641.

Kallberg, Y., Oppermann, U., Jornvall, H., And Persson, B. (2002). Short-chain dehydrogenases/ reductases (SDRS)-Coenzyme-based functional assignments in completed genomes. European Journal of Biochemistry, 269, 4409-4417.

Kavanagh, K. L., Jornvall, H., Persson, B., And Pooermann, U. (2008). Medium- and short-chain dehydrogenase/reductase gene and protein families: The SDR superfamily: Functional and structural diversity within a family of metabolic and regulatory enzymes. Cellular and Molecular Life Sciences, 65, 3895-3906.

Keiner, R., Kaiser, H., NAKajima, K., Hashimoto, T., AND Drager, B. (2002). Molecular cloning, expression and characterization of tropinone reductase II, an enzyme of the SDR family in Solanum Tuberosum (L.). Plant Molecular Biology, 48, 299-308.

Kiem, P. V., Thuy, N. T. K., Anh, H. L. T., Nhiem, N. X., Minh, C. V., Yen, P. H., Ban, N. K., Hang, D. T., Tai, B. H., Tuyen, N. V., Mathema, V. B., Koh, Y. S., AND KIM, Y. H. (2011). Chemical constituents of the rhizomes of Hedychium coronarium and their inhibitory effect on the pro-inflammatory cytokines production LPS-stimulated in bone marrow-derived dendritic cells. Bioorganic \& Medicinal Chemistry Letters, 21, 7460-7465.

Kim, J., Kang, H. G., Jun, S. H., Lee, J., Yim, J., And An, G. (2003). CvADH1, a member of short-chain alcohol dehydrogenase family, is inducible by gibberellin and sucrose in developing watermelon seeds. Plant and Cell Physiol, 44, 85-92.

Kim, Y. J., Shim, J. S., Lee, J. H., Jung, D. Y., Sun, H., IN, J. G., AND YANG, D. C. (2009). Isolation and characterization of a novel short-chain alcohol dehydrogenase gene from Panax ginseng. BMB Reports, 42, 673-678.

Kitaoka, N., Wu, Y., Zi, J., and Peters, R. J. (2016). Investigating inducible short-chain alcohol dehydrogenases/reductases clarifies rice oryzalexin biosynthesis. The Plant Journal, 88, 271-279.

Kumar, S., Tamura, K., and Nei, M. (2004). MEGA3: Integrated software for molecular evolutionary genetics analysis and sequence alignment. Briefings in Bioinformatics, 5, 150-163.

Lan, J. B., Yu, R. C., Yu, Y. Y., and Fan, Y. P. (2013). Molecular cloning and expression of Hedychium coronarium farnesyl pyrophosphate synthase gene and its possible involvement in the biosynthesis of floral and wounding/herbivory induced leaf volatile sesquiterpenoids. Gene, 518, 360-367.

Li, R. H., And FAn, Y. P. (2011). Molecular cloning and expression analysis of a terpene synthase gene, HcTPS2, in Hedychium coronarium. Plant Molecular Biology Reporter, 29, 35-42.

Liu, X. B., Liu, Y. S., Huang, P., Ma, Y. S., Qing, Z. X., Tang, Q., CaO, H. F., Cheng, P., Zheng, Y. J., Yuan, Z. J., Zhou, Y., Liu, J. F., Tang, Z. S., Zhuo, Y. X., Zhang, Y. C., Yu, L. L., H J. L., Yang, P., Peng, Q., AND ZHANG, J. B. (2017). The genome of medicinal plant Macleaya cordata provides new insights into benzylisoquinoline alkaloids metabolism. Molecular Plant, 10, 975-989.

Loh, S. C., Thottathil, G. P., and Отhman, A. S. (2016). Identification of differentially expressed genes and signalling pathways in bark of Hevea brasiliensis seedlings associated with secondary laticifer differentiation using gene expression microarray. Plant Physiology and Biochemistry, 107, 45-55.

Malcomber, S. T., and Kellogg, E. A. (2006). Evolution of unisexual flowers in grasses (Poaceae) and the putative sex-determination gene, TASSELSEED2 (TS2). New Phytologist, 170, 885-899.

Manríquez, D., El-Sharkawy, I., Flores, F. B., El-Yahyaoui, F., Tegad, F., Bouzayen, M., Latche, A., And Pech, J. C. (2006). Two highly divergent alcohol dehydrogenases of melon exhibit fruit ripening-specific expression and distinct biochemical characteristics. Plant Molecular Biology, 61, 675685.

Moummou, H., Tonfack, L. B., Chervin, C., Benichou, M., Youmbi, E., Ginies, C., Latche, A., Pech, J. C., And Wan Der Rest, B. (2012). Functional characterization of SlscADH1, a fruit-ripeningassociated short-chain alcohol dehydrogenase of tomato. Journal of Plant Physiology, 169, 14351444.

Naseron, N. A. H., Lim, K. A., Teh, S. L., Teo, S. S., Leow, A. T. C., Namasivayam, P., and Ho, C. L. (2014). Molecular characterization and homology modeling of a short-chain reductase/dehydrogenase from Gracilaria changii (Rhodophyta). Journal of Applied Phycology, 26, 665-674.

Окамото, S., Yu, F., Harada, H., Okajima, T., Hattan, J., Misawa, N., And Utsumi, R. (2011). A short-chain dehydrogenase involved in terpene metabolism from Zingiber zerumbet. The FEBS Journal, 278, 28922900.

Oppermann, U. C., Filling, C., Berndt, K. D., Persson, B., Benach, J., Ladenstein, R., and Jornvall, H. (1997). Active site directed mutagenesis of 3 beta/17 beta-hydroxysteroid dehydrogenase establishes differential effects on short-chain dehydrogenase/ reductase reactions. Biochemistry, 36, 34-40.

Pan, H. Y., Zhou, R., Louie, G. V., Muhlemann, J. K., Bomati, E. K., Bowman, M. E., Dudateva, N., Dixon, R. A., Noel, J. P., And WAng, X. Q. (2014). Structural 
studies of cinnamoyl-CoA reductase and cinnamylalcohol dehydrogenase, key enzymes of monolignol biosynthesis. The Plant Cell, 26, 3709-3727.

Pang, Y., Song, W. Q., Chen, F. Y., And Qin, Y. M. (2010). A new cotton SDR family gene encodes a polypeptide possessing aldehyde reductase and 3-ketoacyl-Coa reductase activities. Biochemistry (Moscow), 75, 320-326.

Persson, B., Kallberg, Y., Bray, J. E., Bruford, E., Dellaporta, S. L., Favia, A. D., Duarte, R. G., Jörnvall, H., Kavanagh, K. L., Kedishvili, N., Kisiela, M., Maser, E., Mindnich, R., Orchard, S., Penning, T. M., Thornton, J. M., Adamski, J., And OpPermann, U. (2009). The SDR (short-chain dehydrogenase/reductase and related enzymes) nomenclature initiative. Chemico-Biological Interactions, 178, 94-98.

Polichuk, D. R., Zhang, Y. S., Reed, D. W., Schmidt, J. F., ANd Covello, P. S. (2010). A glandular trichomespecific monoterpene alcohol dehydrogenase from Artemisia annua. Phytochemistry, 71, 1264-1269.

Sato, Y., Morita, R., Katsuma, S., Nishimura, M., Tanaka, A., and Kusaba, M. (2008). Two shortchain dehydrogenase/reductases, NON-YELLOW COLORING 1 and NYC1-LIKE, are required for chlorophyll $\mathrm{b}$ and light-harvesting complex II degradation during senescence in rice. The Plant Journal, 57, 120-131.

Scherbak, N., Ala-Haivala, A., Brosche, M., Bawer, N., Strid, H., Gittins, J. R., Grahn, E., Eriksson, L. A., AND STRID, A. (2011). The pea sad short-chain dehydrogenase/reductase: Quinone reduction, tissue distribution, and heterologous expression. Plant Physiology, 155, 1839-1850.

Shen, Q., Zhang, L. D., Liao, Z. H., Wang, S. Y., Yan, T. X., Shi, P., Liu, M., Fu, X. Q., PAn, Q. F., WAnG, Y. L., Lv, Z. Y., Lu, X., Zhang, F. Y., JiAnG, W. M., Ma, Y. N., Chen, M. H., HaO, X. L., Li, L., Tang, Y. L., Lv, G., Zhou, Y., Sun, X. F., Brodelius, P. E., Rose, J. K. C., And TAng, K. X. (2018). The genome of Artemisia annua provides insight into the evolution of asteraceae family and artemisinin biosynthesis. Molecular Plant, 11, 776-788.

Sonawane, P. D., Heinie, U., Panda, S., Gilboa, N. S., Yona, M., Kumar, S. P., Alkan, N., Unger, T., Bocobza, S., Pliner, M., Malitsky, S., Tkachev, M., Meir, S., Rogachev, I., and Aharoni, A. (2018). Short-chain dehydrogenase/reductase governs steroidal specialized metabolites structural diversity and toxicity in the genus Solanum. Proceedings of the National Academy of Sciences of the United States of America, 115, E5419-E5428.

Stavrinides, A. K., Tatsis, E. C., Dang, T. T., Caputi, L., Stevenson, C. E. M., Lawson, D. M., Schneider, B., AND O'CONNOR, S. E. (2018). Discovery of a short chain dehydrogenase from Catharanthus roseus that produces a novel monoterpene indole alkaloid. ChemBioChem, 19, 940-948.

Vainstein, A., Lewinsohn, E., Pichersky, E., And Weiss, D. (2001). Floral fragrance. New inroads Into an old commodity. Plant Physiology, 127, 1383-1389.

Walter, M. H. (1992). Regulation of lignification in defense. In T. Boller and F. Meins (Eds.), Plant gene research: genes involved in plant defense (Vol. 8, pp. 327-352). Vienna, Austria: SpringerVerlag.

WANG, H. B. (2014). Bioinformatics analysis of shortchain dehydrogenase/reductase family SDR110C and genetic transformation of CSSDR110C14 in cucumber. P31-33, Shandong Agricultural University, Jinan, China.

Weeden, N. F., And Provvidenti, R. (1988). A marker locus, adh-1, for resistance to pea enation mosaic virus in Pisum sativum. Journal of Heredity, 79, 128-131.

Wu, T. L. (1994). Phytogeography of the Zingiberaceae. Journal of Tropical and Subtropical Botany, 2, 1-14.

Wu, Z. Y., AND Raven, H. P. (2001). Flora of China 24 (pp. 370-377). Saint Louis, USA: Missouri Botanical Garden Press.

Yu, F. N., Okamto, S., Nakasone, K., Adachi, K., Matsuda, S., Harada, H., Misawa, N., and Utsumi, R. (2008). Molecular cloning and functional characterization of alpha-humulene synthase, a possible key enzyme of zerumbone biosynthesis in shampoo ginger (Zingiber zerumbet). Planta, 227, 1291-1299.

Yue, Y. C., Yu, R. C., And Fan, Y. P. (2014). Characterization of two monoterpene synthases involved in floral scent formation in Hedychium coronarium. Planta, 240, 745-762.

Yue, Y. C., Yu, R. C., And Fan, Y. P. (2015). Transcriptome profiling provides new insights into the formation of floral scent in Hedychium coronarium. BMC Genomics, 16, 470.

Zhang, Y. M., Zhou, W. Z., AND Li, J. F. (2010). Comparative analysis of different RNA isolation methods for dissimilar tissues of sisal. Molecular Plant Breeding, 8, 201-208.

ZhaO, K. H., Zeng, J. L., ZhaO, T. F., Zhang, H. X., Qiu, F., Yang, C. X., Zeng, L. J., Liu, X. Q., Chen, M., LAN, X. Z., AND LiaO, Z. H. (2017). Enhancing tropane alkaloid production based on the functional identification of tropine-forming reductase in Scopolia lurida, a Tibetan medicinal plant. Frontiers in Plant Science, 8, 1745.

Zhou, L., Wang, Y., Ren, L., And Peng, Z. H. (2011). Cloning and expression analysis of dihydroflavonol 4-reductase gene PsDFR1 from tree peony (Paeonia suffruticosa Andr.). Plant Physiology Journal, 47, 885-892.

Zhou, Y., Zhang, L., Gui, J. D., Dong, F., Cheng, S. H., Mei, X., Zhang, L. Y., Li, Y. Q., Su, X. G., 
Baldermann, S., Watanabe, N., and Yang, Z. Y. (2015). Molecular cloning and characterization of a short-chain dehydrogenase showing activity with volatile compounds isolated from Camellia sinensis. Plant Molecular Biology Reporter, 33, 253-263.

Ziegler, J., Brandt, W., Geissler, R., and Facchini, P. J. (2009). Removal of substrate inhibition and increase in maximal velocity in the short chain dehydrogenase/reductase salutaridine reductase involved in morphine biosynthesis. Journal of Biological Chemistry, 284, 26758-26767.

Ziegler, J., Facchini, P. J., Geissler, R., Schmidt, J., Ammer, C., Kramell, R., Voigtländer, S., Gesell, A., Pienkny, S., and Brandt, W. (2009). Evolution of morphine biosynthesis in opium poppy. Phytochemistry, 70, 1696-1707.

Received: 30 January 2020; Accepted: 14 April 2020 


\section{SUPPLEMENTARY MATERIALS}

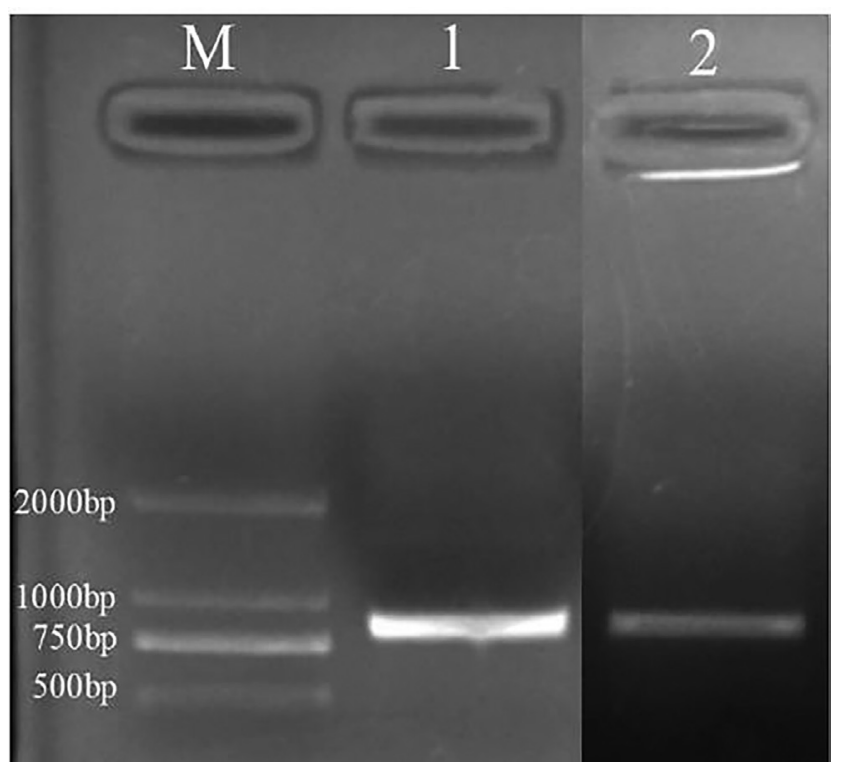

Figure S1. The RT-PCR amplification products of $H c A D H 2$ and $H c A D H 3 . \mathrm{M}=$ DNA DL 2000 Marker; $1=H c A D H 2$ PCR product; $2=H c A D H 3$ PCR product. 
$>$ MK388796.1 $(H C A D H 2)$

CCGGCCTGTTGCCATAAACCACAAGTAGCTCGTCGTTGTGTTTGAGAGAGGAGAGGAGGAAGGTAG ATAGCGAATTAAGGATTATTATCGTCTTCCACTCAGATGGCGGCTGACGGCAGCAACGGTAATGCAGT СССTGCTTCTCCTTCTCGGAGGTTGGAAGGCAAGGTAGCTTTCATAACCGGCGGAGCCGCCGGTTC CGGCGAGGCCACCGCGCGGCTCTTCGTTCTCCACGGCGCGAAGGTGGTGATCGGCGACGTGCGC GACGAGTTCGGCCGCGCAGCGGCGTCCAGCATTGGCGGCGAGGACGTGATCACCTACGTGCACTG CGACGTGTCCAAGGAGGCAGACGTGGAGCGCGCCGTCGACCTGGCGGTGGCCAAGTACGGCCGG CTCGATATCGTTTTCAGCAACGCGGCCGTGCTCGACGAATGCCGCGGCGTCGCCGTCGCGGAGGCC GACGACTTCGACCGCGTGATGGCGGTCAACGTTCGGGGCGTCTTCCTGGGTACCAAGCACGCCGC GCGCGCCATGATGGCGGCGGGCGTGCGGGGAAGCATCATCAACAACGGCAGCGTGGCAACGGTGG TGGCCGGCGTGGCGTCGCACGCCTACGTGGCGTCGAAGCACGCGGTGCTGGGGCTGACGCGGAG CGCGGCGGCGGAGCTCGGCCAGCACGGCATCCGCGTCAACTGCGTGTCGCCTTTCGCGTACGCCA CGTCGTTGGCCTGCGACTTTATTCACATGGACCAGAAACAGATCGAGCAGTTCATCGGCGCAGTCAG CAACCTCAAGGGAGCGGTGCTGAGGGCGGACGACGTGGCGCGCGCCGCTGTCTACCTGGCCAGC GACGAGTCTTGCTACGTCAGCGGACAGAACATCATTATCGACGGCGGCTTTACCGCCGTCAACCACG CCTTTGGCCTCTTCAAGAACTGAGCGATCCCTCGGATCCAGCTGGATTTACCTTATGTCGGTGACGGT CCGAAAAATGATTATGTGCTATTTCAATTGCTCGTCTAAGTTGCTGGTCTTGCTGTGCTTT

$>$ MK388797.1(HCADH3)

TTGACAGAAACCATGCTCGGAATGGCTTTGAGAGTTAAGAGGGGATTGGCGATCAGGACTGGAATTA GAACGCAACAGCAGCAGTTCTCCACCCACCCAACTCCTGCGAGGTTAGCCGGCAAAGTCGCGATCA TCACCGGCGCCGCCAGCGGCGTCGGGAGGGCAACAGCCGCAGAGTTCATCCACCACGGCGCACA GGTCGTCCTCGCAGACATCCAGCACGAGCTCGGCAAGTCTGTTGCCGCCGAGCTCGGCCCCGGCG CCACCTTCGTCCCTTGCGACGTCACCCAGGAGCCCCAAGTCGCTGCCGTCGTCGACCTCGCGGTC GCCAAGCACGGACGCCTGGACATCATGTACAACAACGCCGGCATCTGCGGACCCATGACCTTCGCC GTCACCGACGTCGACCTCACCGAGTTCGACCGCGTCATGGCCGTCAACGTCCGGTCAGTGGTGGCA GGGATCAAACACGCGGCGCGGGTGATGATCCCGCGCCGCGCCGGGAGCATCCTCTGCACGGCGAG CATCACCGGGTTTGTCGGCGGTCTGGCGCCGCTCGCCTATTCTCTGTCGAAGGCGGCGGTGGCGG CTGCAGTGCGGTTATCCGCGGCGGAGCTGAGCAAGCACGGGATAAGGGTGAATTGCATCTCGCCGG CCTCGCTGCCGACGCCATTCGGGATCAAAGCAATCAGGGAAATCCTCCCTGATTTGGAAGAGCAGCG GGCGGTGGAGATGATCGAGCTGTCCTCGGCGGAGTTGGCGGGGACGAAGTGCGAGGTCGAAGACG TGGCGAAGGCAGCGACGTTCTTGGCTTCAGACGAAGCTAAGTACATCAGCGGGCATAATCTCATGGT GGATGGAGGATTCACTACATCTAAACGCTTAAATTTTTCACCAGAGT

Figure S2. Full-length sequence of $H C A D H 2$ and $H c A D H 3$ genes. Nucleotide sequences with green colour $=$ the primer sequences for full cDNA synthesis. Nucleotide sequences with red colour = initiator codon (ATG), terminators (TGA). 


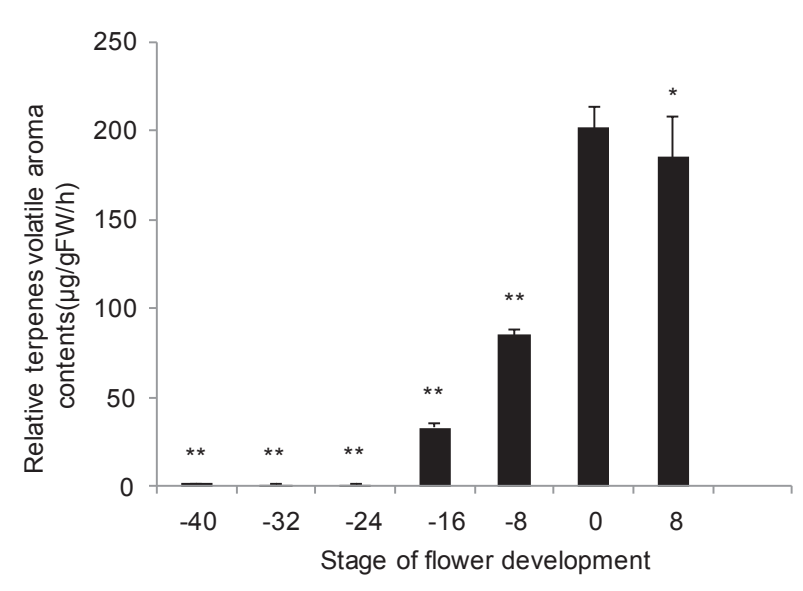

Figure S3. Relative terpenes volatile aroma contents of Hedychium coronarium during flower development. Numbers $= \pm \operatorname{SD}(n=3)$. Asterisks $=$ statistically significant differences compared with the ones with the highest expression level $(* p<0.05 ; * * p<0.01)$.

Table S1. Amino acid residues sequences of comp45280_c0 and comp41433_c0

\begin{tabular}{|c|c|c|c|}
\hline Name & Amino acid residue sequences & Name & Amino acid residue sequences \\
\hline comp45280_c0 & $\begin{array}{l}\text { MAADGSNGNAVPASPSRRLEGKV } \\
\text { AFITGGAAGSGEATARLFVLHGAK } \\
\text { VVIGDVRDEFGRAAASSIGGEDVIT } \\
\text { YVHCDVSKEADVERAVDLAVAKY } \\
\text { GRLDIVFSNAAVLDECRGVAVAEA } \\
\text { DDFDRVMAVNVRGVFLGTKHAAR } \\
\text { AMMAAGVRGSIINNGSVATVVAG } \\
\text { VASHAYVASKHAVLGLTRSAAAEL } \\
\text { GQHGIRVNCVSPFAYATSLACDFIH } \\
\text { MDQKQIEQFIGAVSNLKGAVLRAD } \\
\text { DVARAAVYLASDESCYVSGQNIII } \\
\text { DGGFTAVNHAFGLFKN }\end{array}$ & comp41433_c0 & $\begin{array}{l}\text { MLGMALRVKRGLAIRTGIRTQQQQFSTH } \\
\text { PTPARLAGKVAITGAASGVGRATAAEFI } \\
\text { HHGAQVVLADIQHELGKSVAAELGPGAT } \\
\text { FVPCDVTQEPQVAAVVDLAVAKHGRLDI } \\
\text { MYNNAGICGPMTFAVTDVDLTEFDRVM } \\
\text { AVNVRSVVAGIKHAARVMIPRRAGSILC } \\
\text { TASITGFVGGLAPLAYSLSKAAVAAAVRL } \\
\text { SAAELSKHGIRVNCISPASLPTPFGIKAIRE } \\
\text { ILPDLEEQRAVEMIELSSAELAGTKCEVED } \\
\text { VAKAATFLASDEAKYISGHNLMVDGGFT } \\
\text { TSKRLNFSPE }\end{array}$ \\
\hline
\end{tabular}

Table S2. Primer sequences of $H c A D H 2$ and $H c A D H 3$ used in RT-PCR assays

\begin{tabular}{llllc}
\hline Methods & Forward primer & Reverse primer & $\begin{array}{c}\text { PCR product } \\
\text { size }(\mathrm{bp})\end{array}$ \\
\hline RT PCR & HcADH2 & TCTTCCACTCAGATGGCGGCT & TCAGTTCTTGAAGAGGCCAAA & 849 \\
& HcADH3 & TTGACAGAAACCATGCTCGGAAT & TCACTCTGGTGAAAAATTTAAGCG & 903 \\
$\begin{array}{l}\text { PET-30a:HcADH2 } \\
\text { vector }\end{array}$ & CGCGGATCCATGGCGGCTGACGG & CCCAAGCTTTCAGTTCTTGAAGAGGCCAAAG & \\
$\begin{array}{l}\text { PET-30a:HcADH3 } \\
\text { vector }\end{array}$ & CGCGGATCCATGCTCGGAATG & CCCAAGCTTTCACTCTGGTGAAAAAT & \\
\hline
\end{tabular}


Table S3. Sequences description of accession numbers in GenBank on the phylogenetic tree

\begin{tabular}{|c|c|c|c|}
\hline Accession numbers & Name & Accession numbers & Name \\
\hline AAB57737.1 & Short-chain alcohol dehydrogenase & KM515811.1 & $\begin{array}{l}\text { Short-chain dehydrogenase/ } \\
\text { reductase }\end{array}$ \\
\hline AAM10204.1 & Tropinone reductase & KM515812.1 & $\begin{array}{l}\text { Short-chain dehydrogenase/ } \\
\text { reductase }\end{array}$ \\
\hline AAU20370.1 & Secoisolaticiresinol dehydrogenase & NP_001233856.1 & $\begin{array}{l}\text { Short-chain dehydrogenase/ } \\
\text { reductase }\end{array}$ \\
\hline AB018559.1 & Short-chain alcohol dehydrogenase & OVA14417.1 & $\begin{array}{l}\text { Short-chain dehydrogenase/ } \\
\text { reductase }\end{array}$ \\
\hline ACZ34296.1 & $\begin{array}{l}\text { Short-chain alcohol dehydrogenase/ } \\
\text { reductase }\end{array}$ & PON43718.1 & $\begin{array}{l}\text { Short-chain dehydrogenase/ } \\
\text { reductase }\end{array}$ \\
\hline AJO70763.1 & Alcohol dehydrogenase & PWA82834.1 & Glucose/ribitol dehydrogenase \\
\hline AK103462.1 & $\begin{array}{l}\text { Short-chain alcohol dehydrogenase/ } \\
\text { reductase }\end{array}$ & RWR74505.1 & $\begin{array}{l}\text { Short-chain dehydrogenase/ } \\
\text { reductase }\end{array}$ \\
\hline BAG96093.1 & $\begin{array}{l}\text { Short-chain alcohol dehydrogenase/ } \\
\text { reductase }\end{array}$ & RWR85228.1 & $\begin{array}{l}\text { Short-chain dehydrogenase/ } \\
\text { reductase }\end{array}$ \\
\hline BAG99023.1 & $\begin{array}{l}\text { Short-chain alcohol dehydrogenase/ } \\
\text { reductase }\end{array}$ & RWR94702.1 & Secoisolaticiresinol dehydrogenase \\
\hline BAK09296.1 & $\begin{array}{l}\text { Short-chain alcohol dehydrogenase/ } \\
\text { reductase }\end{array}$ & XP_006366369.1 & Zerumbone synthase \\
\hline DQ384222.1 & Short-chain dehydrogenase/reductase & XP_008811702.1 & Momilactone A synthase \\
\hline DQ384263.1 & Short-chain dehydrogenase/reductase & XP_009404353.1 & Secoisolariciresinol dehydrogenase \\
\hline EEF41657.1 & Short chain alcohol dehydrogenase & XP_009587781.1 & $\begin{array}{l}\text { Short-chain dehydrogenase/ } \\
\text { reductase }\end{array}$ \\
\hline EF184229.1 & Salutaridine reductase & XP_015645551.1 & Momilactone A synthase \\
\hline HQ283448.1 & Dihydroflavonol 4-reductase & XP_018675432.1 & Secoisolariciresinol dehydrogenase \\
\hline KF358245 & Short-chain dehydrogenase/reductase & XP_020246099.1 & Momilactone A synthase \\
\hline
\end{tabular}

Table S4. Primer sequences used in quantitative real-time PCR assays and their characteristics

\begin{tabular}{|c|c|c|c|c|c|}
\hline Gene name & Primer (forward/reverse) $5^{\prime} \rightarrow 3^{\prime}$ & Amplicon $\operatorname{Tm}\left({ }^{\circ} \mathrm{C}\right)$ & $\begin{array}{l}\text { Amplicon } \\
\text { length (bp) }\end{array}$ & $\begin{array}{l}\text { Amplication } \\
\text { efficiency (\%) }\end{array}$ & R2 \\
\hline GAPDH & $\begin{array}{l}\text { TAACATCATTCCCAGCAGCACT } \\
\text { GGTGGATCTCACTGTCAGGCTC }\end{array}$ & 83.20 & 136 & 94.8 & 0.998 \\
\hline HcADH2 & $\begin{array}{l}\text { TGCTACGTCAGCGGACAGAAC } \\
\text { GGACCGTCACCGACATAAGG }\end{array}$ & 90.71 & 128 & 79.4 & 0.991 \\
\hline HcADH3 & $\begin{array}{l}\text { GTCAGTGGTGGCAGGGAT } \\
\text { CAGAGAATAGGCGAGCGG }\end{array}$ & 85.7 & 124 & 99.7 & 0.988 \\
\hline
\end{tabular}

Table S5. Substrate of enzyme catalysed reaction

\begin{tabular}{lll}
\hline Substrate & Number of carbon \\
Geraniol & $\mathrm{C} 10$ & $\mathrm{C} 15$ \\
Farnesol & $\mathrm{C} 10$ & $\mathrm{C}$-Linalool \\
Camphor & $\mathrm{ClO}$ &
\end{tabular}

